\title{
La Cátedra Alfonso Moreno del Departamento de Música de la Universidad Autónoma de Aguascalientes y sus artistas: historia presente y resultados futuros
}

\author{
Leslie Freitas de Torres
}

\section{Resumen}

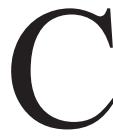
on el afán de diversificar las ofertas educativas-artísticas, en 2009 la Universidad Autónoma de Aguascalientes (UAA) creó el Departamento de Música, el cual, de entre sus varias actividades al fomento del arte, implementó en 2010 la Cátedra Alfonso Moreno con el objetivo de proporcionar a los estudiantes actualización, expansión y reflexión cultural a través del intercambio de experiencias musicales. La cátedra en cuestión ha contado con artistas de amplia trayectoria y reconocimiento, los cuales anualmente han fomentado el fortalecimiento del cuerpo estudiantil e impulsado su formación académica.

Palabras clave: Licenciatura en Música, artistas, estudiantes, Aguascalientes, Alfonso Moreno Luce.

\section{Introducción ${ }^{1}$}

La Ley Orgánica de la Universidad Autónoma de Aguascalientes menciona que "los fines de la Universidad se centran en formar a los estudiantes desde una perspectiva humanista que enfatiza el desarrollo equilibrado e integral de las dimensiones de su persona, lo cual les permita desempeñarse exitosamente como futuros profesionistas y vivir la vida con plenitud y calidad" (UAA, 2015, p. 22). Para lograr dichos propósitos, al igual que facilitar más opciones de carreras en humanidades, en 2009 se creó el Departamento de Música,

1 Este trabajo ha sido realizado en el marco del grupo de investigación Educación y Conocimiento de la Música (UAA-CA-117) con el proyecto "Acciones Académicas en la Historia presente del Departamento de Música de la Universidad Autónoma de Aguascalientes (PIE 20-4)". Agradecimiento a los jefes del Departamento de Música de la UAA, por el apoyo con información sobre el mencionado tema, y a los docentes Dra. Irma Susana Carbajal y Dr. Anderson Rodrigues da Silva. que dependió, en su nacimiento, del Departamento de Letras.

Durante su existencia, ha logrado poner en funcionamiento estrategias educativas para el desarrollo de competencias musicales orientadas a la producción y a la difusión del conocimiento de su alumnado, a través de iniciativas como la Orquesta Filarmónica (OFUAA), Ensamble de Guitarras (EGUAA), Ensamble de Coros, Semana de la Música, Trombón Studio, Seminario Permanente del Departamento de Música (SEMPER), Coloquio de Educación Musical a Nivel Superior o hasta la propia Cátedra Alfonso Moreno (Carbajal, Correa y Capistrán, 2017, pp. 5-7).

Con el objetivo de destacar la importancia de la creación de la Cátedra Alfonso Moreno del Departamento de Música, de los músicos que la impartieron y su impacto en la formación de los universitarios, se ha desarrollado este artículo. Por un lado, se da a conocer la razón del nombre otorgado a la Cátedra Alfonso Moreno y el rigor en 
la selección del profesorado invitado y, por otro, se exhibe un listado cronológico de las personalidades que han pasado por la Cátedra y algunos de sus resultados frente a los universitarios.

\section{La Cátedra Alfonso Moreno}

El artista Alfonso Moreno Luce nació el 9 de enero de 1949 en Aguascalientes. A los cuatro años inició sus estudios musicales bajo los auspicios de su padre, Rafael Moreno Dauzón (Tapia, 1991, pp. 213-214). Posteriormente ingresó al Conservatorio de Música de Xalapa, donde cursó violín y composición. En estos años, el músico en cuestión ya presentaba una predisposición hacia la guitarra, puesto que una de sus primeras composiciones fue para este instrumento. En tal sentido, en 1964 tomó clases en el Estudio de Arte Guitarrístico en la Ciudad de México con el argentino Manuel López Ramos, personaje clave en su formación y consolidación artística.

Durante su trayectoria recibió varios premios, realizó innumerables recitales e impartió distintos cursos. Por poner algunos ejemplos, en 1968, fue galardonado con el primer lugar en el Concurso Internacional de Guitarra en París; en 1974, participó en la Semana de Artistas Internacionales de Nueva York; entre 1977 y 1982, grabó algunos discos distribuidos por compañías como EMI capital de Inglaterra, Discos Forlane de Francia y Global Entertainment de México y, en 1995, fundó la "Orquesta de Guitarras de Xalapa", con la que llevó a cabo giras por la República Mexicana (Benítez, 2019).

Frente a este notable currículo y la representatividad artística de la población aguascalentense manifiesta en su persona, en 2010 se creó la Cátedra Alfonso Moreno, cuyo afán ha sido vincular el Departamento de Música de la alma máter hidro-

《En 2010 se creó la Cátedra Alfonso Moreno, cuyo afán ha sido vincular el Departamento de Música de la alma máter hidrocálida con académicos y artistas de tan reconocida talla como la del músico Moreno, e igualmente brindar a los universitarios formación complementaria》 cálida con académicos y artistas de tan reconocida talla como la del músico Moreno, e igualmente brindar a los universitarios formación complementaria (UAA, 2018).

La cátedra en cuestión consiste en la visita de un músico de reconocimiento nacional o internacional al Departamento de Música con el fin de que comparta sus conocimientos y sus experiencias artísticas con el alumnado y profesorado. Para ello, anualmente se llevan a cabo algunos procedimientos para la elección del invitado, los cuales consisten en: 1) la propuesta del nombre del músico que tendrá la cátedra, hecha por el jefe del departamento al decano del centro; 2) la autorización de la Comisión Ejecutiva de dicho centro a la misma, donde se considera la trayectoria del artista; y 3) el envío de la carta invitación al seleccionado. Cabe señalar que los músicos elegidos imparten exposiciones o talleres sobre temas relacionados con sus habilidades musicales, e igualmente ofrecen un concierto durante las actividades del propio Departamento, como en la "Semana de la Música".

\section{Artistas que han participado de la Cátedra Alfonso Moreno}

Afirman De Peña y Jiménez que "las universidades son instituciones que han sido partícipes desde sus orígenes de la creación del futuro, ya sea como formadoras de las nuevas generaciones o como generadoras de nuevos conocimientos" (2014, p. 149). Pensando en ello, la Cátedra Alfonso Moreno, durante sus diez años de realización, ha contado con grandes personalidades de la música académica que han compartido sus conocimientos y experiencias con los estudiantes (México es Cultura, 2018), como el propio Alfonso Moreno en 2010, quien dirigió la orquesta de guitarras que se organizó, en ese entonces, con alumnos de la primera generación de la Licenciatura en Música de la UAA, hecho que fomentó el alma colectiva de los universitarios y fue clave en el mejoramiento de sus prácticas instrumentales.

En los años de 2011 y 2012, estuvieron a cargo los compositores Mario Lavista y Manuel Jorge de Elías, ambos, además de tener trayectorias relucientes, igualmente compusieron obras para diversos géneros, desde música para instrumento solo hasta sinfonías. Durante la impartición de la cátedra, 
dichos artistas brindaron a los universitarios conocimiento de la composición, campo de aplicación musical novedoso en la UAA, debido a que aún no figura en el plan de estudios de la carrera de Música.

En 2013, el exdirector de la Orquesta Sinfónica de Aguascalientes, Román Revueltas, ocupó la cátedra. El percusionista chileno Raúl Vergara Montoya, asociado principal de la Orquesta Filarmónica de Seúl y encargado del programa de liderazgo de la Orquesta Juvenil de las Américas, en 2014, compartió parte de su trayectoria profesional con los estudiantes del Departamento de Música. Ambos artistas posibilitaron la ampliación de la red de contactos profesionales de los estudiantes, red que les puede ayudar en una colocación laboral en el futuro.

Sergio Cárdenas, quien ha realizado actuaciones como director invitado en notables agrupaciones orquestales de América, Asia y Europa (Berumen, 2019), fue el convidado en 2015. Durante la Semana de la Música del año siguiente, el trompetista Juan Manuel Arpero, originario de Guanajuato, impartió la conferencia denominada "La trompeta mexicana: su identidad e historia", donde manifestó a los futuros profesionistas la importancia del estudio de la musicología histórica para el desarrollo artístico.

En 2017 y 2018, la cátedra estuvo bajo la dirección de Javier Álvarez Fuentes, compositor especializado en música de concierto, electroacústica y música para cine, y del guitarrista mexicano Rodrigo Nefthalí López Alarcón. En su última edición, contó con la participación del compositor y flautista mexicano Wilfrido Damián Terrazas Pérez. Conviene añadir que, debido a las medidas sanitarias ocasionadas por el Covid-19, en el año de 2020 el compositor, director y musicólogo Luis Jaime Cortez Méndez, fue el artista invitado, quien realizó tres conferencias en línea y expuso temas todavía pendientes de investigación y que servirían a pesquisas futuras de los universitarios.

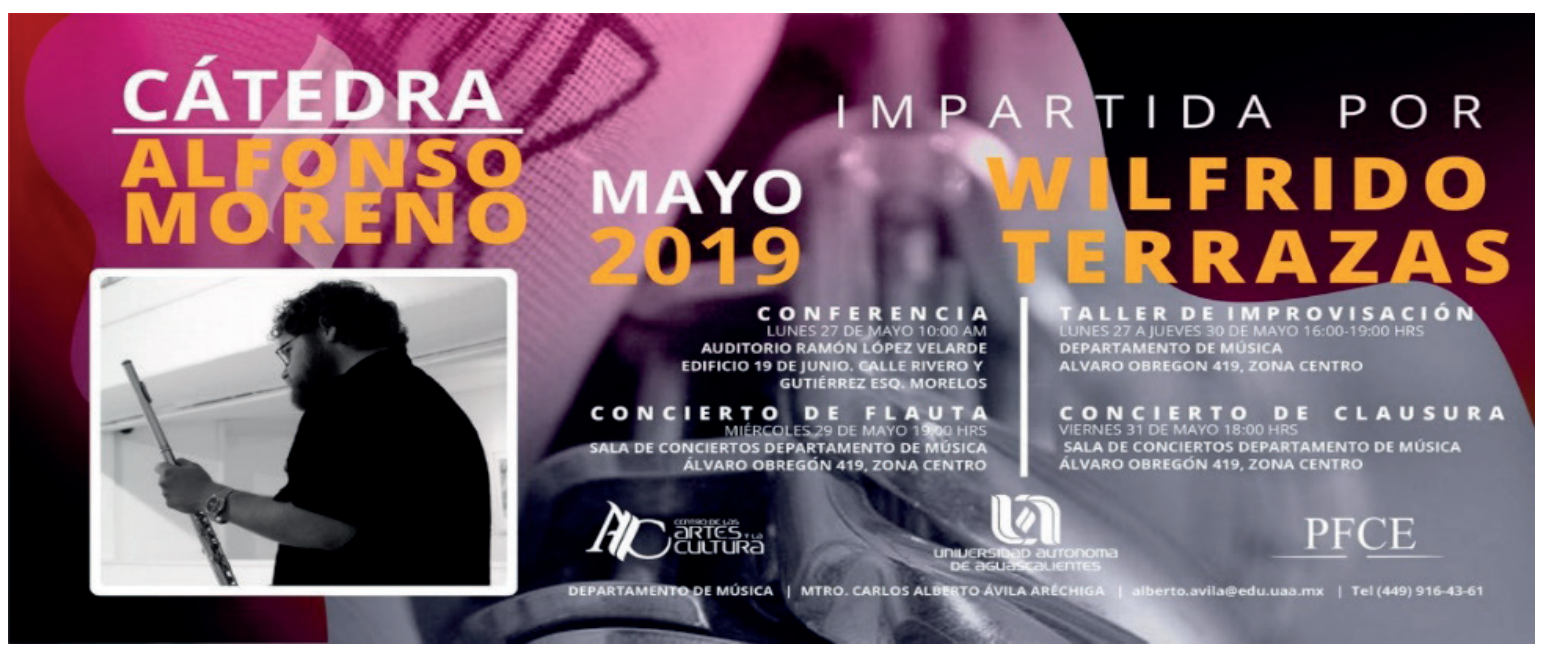

Fuente: Imagen tomada del portal del evento Cátedra Alfonso Moreno, UAA, 2019.

\section{Conclusiones}

Tal como señala Jorquera (2017), el alumnado sólo disfruta de buenas prácticas musicales a través de una adecuada preparación. Por ello, la Cátedra Alfonso Moreno ha sido la piedra angular en el impulso de la formación músico-educativa de los estudiantes de la Licenciatura en Música de la UAA.
《La Cátedra Alfonso Moreno, durante sus diez años de realización,

ha contado con grandes personalidades de la música académica que han compartido sus conocimientos y experiencias con los estudiantes $\gg$ 
Desafortunadamente, son exiguas las iniciativas mexicanas que comparten similitudes con dicha Cátedra, los modelos que más se acercan son la Cátedra Arturo Márquez de Composición Musical, impartida por la Universidad Nacional Autónoma de México, que fue creada con el objeto de contribuir a la instrucción de los jóvenes compositores mediante la tutoría del maestro Arturo Márquez (Música en México, 2016) o la Cátedra José Hernández de la Universidad de Veracruz, que en 2019 fue instaurada con el propósito de reforzar el sentimiento de identidad y continuidad de la expresión musical popular de los mariachis (Pérez, 2019).
Por lo tanto, anualmente la Cátedra Alfonso Moreno ha tenido un impacto directo en el alumnado de la carrera de Música de la UAA, puesto que le ha proporcionado el intercambio de experiencias $\mathrm{y}$, a la vez, su complemento y fortalecimiento de la formación académica y profesional, posibilitando que la historia presente genere frutos futuros mediante la expansión del conocimiento hacia las distintas vertientes musicales, la actualización de las tendencias musicales, el fomento de una expectativa positiva frente a la profesión y, lo más importante, la preparación de músicos comprometidos con el quehacer artístico en un contexto contemporáneo.

\section{Fuentes de consulta}

Benítez, M. (2019). Entrevista al maestro Alfonso Moreno y sus caminos con la guitarra. NDN Cultura. Recuperado de https://www.adncultura.org/entrevista-alfonso-moreno-y-su-guitarra.

Berumen, A. (2019). Sergio Cárdenas, un tamaulipeco de clase mundial. El Sol de Tampico. Recuperado de https://www.elsoldetampico.com.mx/cultura/sergio-cardenas-un-tamaulipeco-de-clase-mundial-3857106.html.

Carbajal, I., Correa, J. y Capistrán, R. (2017). Historia reciente de la educación musical de nivel superior en México: un acercamiento a los retos curriculares de la licenciatura en Música de la Universidad Autónoma de Aguascalientes. Actas del Congreso Nacional de Investigación Educativa, 1-11. San Luis Potosí: Comie. Recuperado de http://www.comie.org.mx/congreso/memoriaelectronica/v14/ doc/0351.pdf.

De Peña, C. y Jiménez, M. (2014). Internacionalización y cooperación universitaria: el caso de Cátedra Europa. Investigación \& Desarrollo, (22), 146-167.

Jorquera, C. (2017). Las buenas prácticas como reflejo del estado de la educación musical: una revisión bibliográfica. Revista Internacional de Educación Musical, (5), 71-83.

México es Cultura. (2018). La infinita coincidencia. México es Cultura. Recuperado de https://www. mexicoescultura.com/actividad/191836/la-infinita-coincidencia.

Música en México. (2016). Convocatoria a la Beca Cátedra Extraordinaria “Arturo Márquez de Composición Musical”. Música en México. Recuperado de https://musicaenmexico.com.mx/convocatoriala-beca-catedra-extraordinariaarturo-marquez-composicion-musical/.

Pérez, A. (2019). Instaura la Universidad Veracruzana la Cátedra José Hernández. Alcalorpolítico.com. Recuperado de https://www.alcalorpolitico.com/informacion/instaura-la-universidad-veracruzana-la-catedra-jose-hernandez-280231.html\#.X1zDcGhKjIU.

Tapia, S. (1991). Música y músicos en México. Sinaloa: Panorama Editorial.

UAA. (2015). Ley Orgánica de la Universidad Autónoma de Aguascalientes. Estatuto de la Ley Orgánica. Recuperado de https://docsgc.uaa.mx.

UAA. (2018). 45 cosas que debes saber acerca de la Universidad. Gaceta Universitaria, (133), 20-23. Universidad Autónoma de Aguascalientes.

UAA. (2019). Cátedra Alfonso Moreno. Portal de Evento. Recuperado de https://www.uaa.mx/portal/evento/catedra-alfonso-moreno/. 